\title{
The Educational Dilemma of Rural Left-behind Children and the Construction of Care System
}

\author{
Guoqing Tao \\ Ginling College, Nanjing Normal University, Nanjing, China
}

\begin{abstract}
Left-behind children in rural areas are a special group produced in the process of urbanization in China. Left-behind children lack parental care in life and education. This article investigates whether left-behind children have an impact on the performance and cognitive abilities of left-behind children, and the magnitude of the influence. The results show that only left-behind children whose mothers go out and whose fathers are at home will have a significant decline in performance; the absence of parents will have a significant negative effect on the children's cognitive ability. Based on the above education dilemmas for left-behind children, this article proposes to build a care system for left-behind children: on the one hand, the government, market and social forces should be integrated to ensure the effective connection of urban and rural education resources; on the other hand, through the national child welfare policy and local social welfare provision organically combine to promote the development of left-behind children.
\end{abstract}

Keywords: Left-behind children, Cognitive ability, Performance, Social welfare.

\section{Introduction}

According to the "China Floating Population Development Report 2018", starting from 2015, new changes have taken place in the scale of the floating population. The scale of the floating population in the country has changed from a continuous increase to a slow decline. In 2015, the National Bureau of Statistics announced that the total number of floating population in the country was 247 million, a decrease of about 6 million from 2014; the scale of the national floating population in 2016 decreased compared with 2015.In 2017, it continued to decrease by 820,000 .

Closely related to the floating population is the problem of left-behind children. According to the National Information Management System for Rural Left-behind Children and Children in Distress, the Ministry of Civil Affairs showed that there were 6.97 million rural left-behind children nationwide in 2018 , a decrease of $22.7 \%$ compared with the survey data in 2016. From November 2016 to January 2017, the former Migrant Population Department of the National Health and Family Planning Commission cooperated with UNICEF to organize the health of left-behind children in poverty-stricken areas in 27 counties (districts) in 12 provinces (regions, cities) across the country service needs assessment survey. The survey found that grandparents are the main caregivers of left-behind children, accounting for more than $90 \%$, with an average age of 59 years old, and more than $70 \%$ of those with a primary school education or below. Due to low education and old age, grandparents tend to pay more attention to their children's physical needs and ignore their emotional needs. In addition, left-behind children with multiple mathematics age basically rely on themselves to manage their daily lives, and at the same time have to undertake some housework and farm work. Based on the different choices of the family, children are divided into different groups: left-behind children and non-left-behind children. Based on a variety of data surveys, the learning performance of rural left-behind children is significantly lower than that of non-left-behind children.
However, education equity is the cornerstone of social equity, and the issue of education equity is a prominent issue in the transition period of our society. Left-behind children, as a special vulnerable group that emerged during the transitional period of China's economic development, the core issue is education, which is an objective manifestation of the comprehensiveness of multiple contradictions and conflicts. The report of the 18th National Congress of the Communist Party of China clearly pointed out: Vigorously promote education equity, rationally allocate educational resources, focus on rural, remote, impoverished, and ethnic areas, support special education, increase the level of funding for students from poor families, and actively promote equal access to education for children of migrant workers. So that every child can become a useful talent. American scholar Philip Combs once warned: "If education inequality is not reduced more quickly and more quickly, it will become a kind of social and economic progress. Increasingly serious obstacles have become the cause of political turmoil in many countries[1]." It can be seen that the education of left-behind children is not only a quality education problem, but also a social issue related to fairness and stability. The dilemma of children's education is an urgent need to promote the balanced development of compulsory education and realize social justice.

Therefore, this article intends to study the impact of parents' going out on the academic performance and cognitive abilities of rural left-behind children, conduct empirical analysis on the educational dilemma of left-behind children and put forward targeted suggestions, and believes that it is a proper way to build a care system for left-behind children.

\section{Literature Review}

\subsection{Solving the Theoretical Basis for the Education} Dilemma of Left-behind Children

To solve the educational dilemma is to provide educational 
support, which mainly refers to the assistance of various means and measures taken by the state, social groups or individuals to provide material, funds, services and other aspects of education provided by the state, social groups or individuals in order to guarantee equal access to education for disadvantaged groups. As a disadvantaged group in education, left-behind children need more support and assistance from the society, schools and other external forces to help them realize their own value when they cannot get rid of the predicament on their own.

2.1.1 Ethics of care-the logical starting point for the education of left-behind children

Care ethics emerged in the United States in the late 1970s and early 1980s. It is an important theory of contemporary Western ethics. The well-known American philosopher and educator Neil Noddings has conducted in-depth exploration and systematic improvement of caring ethics from the perspective of moral philosophy, and successfully applied this theory to the field of moral education practice, and the caring ethics and moral education model was born. Care ethics believes that care comes from love, responsibility and moral ideals, which means being responsible for something or someone, protecting their interests, and promoting their development, providing a new perspective for studying the education of left-behind children[2].

Care ethics pays attention to the general and basic characteristics of the existence of children as a person. It takes human existence as the prerequisite to show concern for the true needs of children and reveals the significance of the life world as the basis of children's moral education. From the perspective of care ethics, caring and serving left-behind children and building an educational support system are an ethical requirement for the whole society. This ethical requirement is different from the nature of the natural care that parents do not need to make ethical efforts for their children. All parties in society who have no direct natural blood relationship with left-behind children are required to make ethical efforts. Therefore, caring for left-behind children and building an education support system is essentially a kind of ethical care for the disadvantaged group of left-behind children.

2.1.2 Educational equality-the guiding ideology of education for left-behind children

As the Swedish educator Tolston Husen said: "Equality has become a key word in policy discussions on education issues, both domestically and internationally, for several years." Husen's education equality Thought includes three meanings: starting point, process and result equality: first, "equality" can first refer to the individual's starting point; second, "equality" can also refer to the intermediary stage, that is, equal treatment in the education process; Third, "equality" can also refer to the final goal or a combination of these three aspects. American scholar James Coleman pointed out in the famous Coleman report "Equal Educational Opportunity" that the goal of pursuing equal educational opportunity is to provide all students with educational resources and resources that will help them achieve certain academic achievements. Education process. The inspection of school education quality should focus on the extent to which it can liberate students' potential, so that students will not enter an unequal educational environment due to differences in background and social environment, and ultimately reduce students' dependence on opportunities for their social background.

For a developing country like our country where the development of education is not evenly balanced, the priority at this stage of left-behind children's education equity is to provide active compensation and assistance to enable left-behind children with low socioeconomic status to obtain educational support, enhance the ability to participate in society. Of course, due to different economic, social, and cultural developments in different regions, the assistance and compensation most in need of education will vary. In the context of China's current creation of a harmonious society, a comprehensive analysis and interpretation of the Coleman report has important guiding value for current educational equity issues and the practical exploration of the balanced development of education, as well as the education support for left-behind children.

\subsection{The Impact of Parents' Going out on the Education of Left-behind Children}

The research on left-behind children mainly focuses on the impact of whether parents keep their children at home or move with them. These impacts are concentrated in education, health, and psychology. In the study of educational conditions, the conclusions are inconsistent.

\subsubsection{Positive impact}

Some studies suggest that parents' going out to work has a positive impact on children's education. Duan Chengrong, Lu Lidan, and Wang Zongping (2013) believe that left-behind has a positive effect on children's education. The increased income of parents going out to work will increase their children's educational investment, making left-behind children perform better than non-left-behind children in rural areas[3]. In addition, the results of Duan Chengrong, Lv Lidan, and Wang Zongping (2014) showed that left-behind children's language scores were higher than non-left-behind children by about 1.73 points, and their math scores were higher than non-left-behind children by about 2.14 points[4]. Chengchao Zhou and Sean Sylvia (2015) extracted data from a comprehensive data set covering 141,000 children in 10 provinces and analyzed nine indicators of health, nutrition and education. It was found that in all nine indicators, the performance of left-behind children was better than those of children living with or living with their parents[5]. Some scholars also conduct research from the perspective of enrollment rate. Zhang Liang (2017) used the longitudinal data of the Chinese Family Tracking Survey in 2010 and 2012 to examine the changes in the schooling status of children aged 10-15 in rural areas after two years. The study found that whether or not parents go out to work has no significant effect 
on the probability of children in rural schools continuing to attend school after two years[6].

\subsubsection{Negative influence}

Another part of the research suggests that staying behind has a bad influence on children's performance.

Wan Jin (2019) explored the reasons for the education problems of left-behind children from the perspective of relative deprivation. The results showed that parents' going out to work makes their children feel strongly about their parents. Compared with non-left-behind children, they have a strong sense of deprivation, which leads to Left-behind children experience feelings of loss, dissatisfaction and even resentment. This psychological feeling directly affects the attention and initiative of the left-behind children in learning, which leads to the lack of interest in learning and the decline in academic performance of some left-behind children[7].

Some scholars have conducted research from the perspective of the effectiveness of guardian supervision. Hu Feng and Li Shantong (2009) pointed out that since most of the left-behind children are under the supervision of other guardians, other guardians' supervision of children is not as effective as parent's supervision of children, causing negative consequences effect[8].

Regarding the endogenous problems of the migrant population, Li Yunsen (2013) applied the propensity score matching method to control the self-selection problem of parents going out. Using the data from the 2000 Gansu Children and Family Survey, the impact of parents going out on the performance of left-behind children was analyzed. The conclusion shows that one or both parents going out for more than half a year have a significant negative impact on whether the child can enter the $20 \%$ grade in Chinese, mathematics and cognitive ability test scores in the top 10\%[9].

In addition, fathers and mothers going out have different effects on the performance of left-behind children. Qin Min and Zhu Xiao (2018) Parents' going out has an adverse effect on the study and life of these children. The study found that mother's outing arrangements have extremely negative effects on rural left-behind children[10]. Xu Qi (2018) used the traditional gender division of labor of "men dominate the outside and women dominated the interior", combined with an in-depth analysis of the baseline survey data of the "China Education Tracking Survey", and found that only the mothers go out alone to learn about left-behind children in rural areas Performance has a significant negative impact[11]. Yang Juhua and Duan Chengrong (2008) used the 2000 census data of $0.95 \%$ to compare the educational opportunities of migrant children, left-behind children and other children aged 11-14 in rural areas. The analysis results show that compared with other children, the educational opportunities of left-behind children are significantly higher; the educational opportunities of left-behind children with their mothers have been improved, but the educational opportunities of left-behind children with their fathers have been significantly reduced[12].

Similar conclusions have been reached in foreign studies. Mckenzie and Rapoport (2006) conducted a study on the enrollment rate. Their analysis of left-behind children in Mexico found that parents working outside would reduce the enrollment rate of children and make their learning worse[13]. Wen and Lin (2012) analyzed the enrollment rate, and they found that staying behind lowered the enrollment rate[14].

The conclusions of the above literature are different, but most scholars advocate that parents going out will have a certain negative impact on left-behind children.

\section{Data and Variables}

\subsection{Data Source}

This article uses the baseline survey data of the "China Education Tracking Survey" in the 2013-2014 school year, and plans to start a new survey group starting from the seventh grade in the tenth year (2023). CEPS is a national survey data, sponsored by Renmin University of China. CEPS took junior high school students as the survey object, took the proportion of the floating population and the average education level as stratified variables, and selected 28 county-level units from the country through random sampling. Subsequently, with schools as the basic unit, 112 schools were randomly selected from the selected counties and cities, with a total of about 20,000 students in 438 classes. CEPS surveyed the selected students, parents, and schools in the form of questionnaires. Including data on four levels: students, parents, classes, and schools. The student questionnaire involves three aspects: personal situation, family situation and school situation. The parent questionnaire involves family education, the relationship between parents and the school, school education, the basic situation of the child, and the situation of parents, family and community. The class level includes the class teacher questionnaire and the class teacher questionnaire. The class teacher questionnaire involves teaching work, class teacher work, basic information of the class teacher and teacher's concept, the class teacher questionnaire involves teaching work, teacher basic information and concepts, and the school leader questionnaire at the school level involves basic school information, Student information, teacher information, enrollment and enrollment status, management information, etc. At the same time, the survey also covers students' comprehensive cognitive ability test (the test paper is an internationally standardized cognitive ability test paper) and the students' important examinations (mid-term examination, high school entrance examination, college entrance examination, etc.) scores.

For the identification of left-behind children in rural areas, firstly, the nature of the child's hukou is to distinguish whether the child is agricultural or non-agricultural; secondly, whether the child is migrant or not is judged by the questionnaire in the personal questionnaire whether the child is migrant or not; and finally whether the parent is the same as 
the child live to determine whether to stay behind. After being identified, there are 2436 left-behind children in rural areas. Among these children, the stay-behind situation is also different. According to previous studies, especially the survey by Yang Juhua and Duan Chengrong (2008), they can be divided into three categories: only the father is out, only the mother is out, and both parents are out.

\subsection{Model and Variable Description}

\subsubsection{Dependent variable}

$Y_{i}$ is the dependent variable, namely the midterm test scores of Chinese, mathematics and English and cognitive ability of left-behind children and non-left-behind children in rural areas. In addition, in order to make the scores between regions comparable, the CEPS data also provides standardized test scores for students. Standardize the scores with an average of 70 points and a standard deviation of 10 points. Therefore, this article's standardized score is the final dependent variable.

\subsubsection{Independent variables}

The core explanatory variable of this article is $l e f t_{i}$, the child's stay-behind state, further subdivided into: mother is at home, father is at home, and parents are not at home. The independent variables are manipulated into dummy variables ( 1 at home, 0 when not at home), and regressions are performed separately, and a total of three regressions are performed.

\subsubsection{Control variables}

$X_{i}$ is a series of control variables. The selection of factor variables in this paper is also carried out from three levels of individual, family and school. The final selected factors are: at the personal level, the child's gender ( 1 is male, 0 is female), age, whether he has a serious illness before elementary school ( 1 is a serious illness, 0 is not a serious illness), and whether he is an only child Female ( 1 is the only child, 0 is the other); at the family level, the education level of the father and mother (due to the complexity of classification and data, this article adopts a virtual measurement method for the level of education, so the average value is a few tenths ), family financial status (measured by the amount of pocket money per week), the severity of the homework test ( 1 is severe, 0 is not severe); at the school level, the school ranks ( 1 is the best, 0 is other).

\subsubsection{Model}

This article mainly examines the impact of parents going out on the performance of left-behind children in rural areas. Since both explanatory variables and explanatory variables have been indexed, it is assumed that the two conform to the following linear regression model:

$$
Y_{i}=c+\alpha l f e f_{i}+\beta X_{i}+\varepsilon_{i}
$$

\section{Descriptive Statistics and Analysis Results}

\subsection{Descriptive Statistics}

The basic statistical description results are shown in Table 1.

Table 1: Basic statistics description of left-behind and non-left-behind children in rural areas

\begin{tabular}{|c|c|c|c|c|c|c|}
\hline & \multicolumn{3}{|c|}{$\begin{array}{c}\text { Rural left-behind } \\
\text { children }\end{array}$} & \multicolumn{3}{|c|}{$\begin{array}{c}\text { Rural non-left-behind } \\
\text { children }\end{array}$} \\
\hline & obs & mean & std.dev & obs & mean & std.dev \\
\hline $\begin{array}{c}\text { Cognitive } \\
\text { performance }\end{array}$ & 2,436 & -0.2379 & 0.7791 & 6,212 & -0.1241 & 0.8168 \\
\hline $\begin{array}{c}\text { Chinese } \\
\text { performance }\end{array}$ & 2,355 & 69.5008 & 10.1836 & 6,074 & 69.6893 & 10.0416 \\
\hline Math score & 2,357 & 69.6339 & 10.2405 & 6,062 & 69.7585 & 9.9853 \\
\hline English score & 2,358 & 69.4141 & 10.3226 & 6,073 & 69.7265 & 9.9853 \\
\hline Gender $($ male $=1)$ & 2,436 & 0.5374 & 0.4987 & 6,212 & 0.5087 & 0.5000 \\
\hline Age & 2,379 & 13.7503 & 1.3362 & 6,086 & 13.6577 & 1.2627 \\
\hline $\begin{array}{c}\text { Serious } \\
\text { illness }(\text { yes }=1)\end{array}$ & 2,436 & 0.1827 & 0.3865 & 6,212 & 0.1265 & 0.3325 \\
\hline $\begin{array}{l}\text { Is it an only } \\
\text { child(yes=1) }\end{array}$ & 2,436 & 0.2110 & 0.4081 & 6,212 & 0.2893 & 0.4535 \\
\hline $\begin{array}{l}\text { Mother who } \\
\text { graduated from } \\
\text { elementary school } \\
\text { and below }\end{array}$ & 2,436 & 0.4150 & 0.4928 & 6,212 & 0.3121 & 0.4634 \\
\hline $\begin{array}{l}\text { Mother graduated } \\
\text { from junior high } \\
\text { school }\end{array}$ & 2,436 & 0.4470 & 0.4973 & 6,212 & 0.5146 & 0.4998 \\
\hline $\begin{array}{l}\text { Mother graduated } \\
\text { from high school }\end{array}$ & 2,436 & 0.0172 & 0.1302 & 6,212 & 0.0282 & 0.1655 \\
\hline $\begin{array}{l}\text { Mother's college } \\
\text { degree or above }\end{array}$ & 2,436 & 0.1203 & 0.3254 & 6,212 & 0.1436 & 0.3507 \\
\hline $\begin{array}{l}\text { Father who } \\
\text { graduated from } \\
\text { elementary school } \\
\text { and below }\end{array}$ & 2,436 & 0.4150 & 0.4928 & 6,212 & 0.3121 & 0.4634 \\
\hline $\begin{array}{l}\text { Father graduated } \\
\text { from junior high } \\
\text { school }\end{array}$ & 2,436 & 0.4470 & 0.4973 & 6,212 & 0.5146 & 0.4998 \\
\hline $\begin{array}{l}\text { Father graduated } \\
\text { from high school }\end{array}$ & 2,436 & 0.0172 & 0.1302 & 6,212 & 0.0282 & 0.1655 \\
\hline $\begin{array}{l}\text { Father's college } \\
\text { degree or above }\end{array}$ & 2,436 & 0.1203 & 0.3254 & 6,212 & 0.1436 & 0.3507 \\
\hline $\begin{array}{l}\text { Whether living with } \\
\text { grandparents(yes=1) }\end{array}$ & 2,334 & 0.5219 & 0.4996 & 5,941 & 0.3015 & 0.4589 \\
\hline $\begin{array}{c}\text { Pocket money every } \\
\text { week }\end{array}$ & 2,322 & 28.0801 & 51.9373 & 5,881 & 30.0879 & 45.6646 \\
\hline $\begin{array}{c}\text { Strict homework } \\
\text { test }(\text { yes }=1)\end{array}$ & 2,436 & 0.9310 & 0.2534 & 6,212 & 0.9458 & 0.2265 \\
\hline School rank(best $=1)$ & 2,436 & 0.1424 & 0.3496 & 6,212 & 0.1685 & 0.3744 \\
\hline
\end{tabular}

In terms of performance, it can be seen that the cognitive ability of rural left-behind children is lower than that of 
non-left-behind children, indicating that left-behind children are insufficient due to the lack of cognitive ability of their parents. In the results of Chinese, Mathematics, and English, the difference between left-behind children and non-left-behind children is not big, about 69 points.

At the individual level, the majority of left-behind children in rural areas are boys, accounting for about $54 \%$ of the left-behind children. Because the survey object of this data is the first grade and third grade students, their average age is about 13 years old. In terms of physical health, the probability of serious illnesses for left-behind children in rural areas is higher than that for non-left-behind children. Perhaps because of the lack of parental care, other guardians have failed to provide better care. Among all left-behind children, only children accounted for $21 \%$. Because there are many brothers and sisters, parents cannot bring their children with them, so more non-only children are left behind.

In terms of families, the education level of parents of children in rural areas is mainly at the elementary and junior high school levels, and the probability of graduating from high school is lower. On the contrary, the probability of college and above is higher than the probability of graduating from high school. In terms of pocket money for children, the weekly pocket money for left-behind children is about 28 yuan, and the pocket money for non-left-behind children is 30 yuan. Because parents of left-behind children go out to work, their income is invested in their children's education and life. In dealing with children's learning, parents have adopted strict measures. Whether left-behind children or non-left-behind children, parents pay very high attention to their education and learning.

In terms of schools, the probability of left-behind children studying in the best schools is $14 \%$, and the probability of non-left-behind children is $17 \%$, the difference is not big.

In order to analyze the variables of left-behind children in more detail, the variables are described according to the classification of left-behind children. As shown in Table 2, the left-behind children are divided into fathers at home, mothers at home, and parents not at home.

Table 2 Basic statistics description by sort

\begin{tabular}{|c|c|c|c|c|c|c|c|c|c|}
\hline & \multicolumn{3}{|c|}{$\begin{array}{l}\text { Left-behind children with } \\
\text { father at home }\end{array}$} & \multicolumn{3}{|c|}{$\begin{array}{l}\text { Left-behind children with mother } \\
\text { at home }\end{array}$} & \multicolumn{3}{|c|}{$\begin{array}{c}\text { Left-behind children whose } \\
\text { parents are not at home }\end{array}$} \\
\hline & obs & mean & std.dev & obs & mean & std.dev & obs & mean & std.dev \\
\hline Cognitive performance & 293 & -0.3302 & 0.7790 & 883 & -0.1755 & 0.7710 & 1,260 & -0.2601 & 0.7822 \\
\hline Chinese performance & 282 & 66.7567 & 12.2042 & 856 & 69.6516 & 9.6473 & 1,217 & 70.0307 & 9.9428 \\
\hline Math score & 284 & 66.5083 & 10.6597 & 858 & 70.1485 & 9.9111 & 1,215 & 70.0012 & 10.2508 \\
\hline English score & 284 & 66.1453 & 11.1542 & 857 & 69.4770 & 10.1339 & 1,217 & 70.1326 & 10.1132 \\
\hline Gender $($ male $=1)$ & 293 & 0.6280 & 0.4842 & 883 & 0.5436 & 0.4984 & 1,260 & 0.5119 & 0.5001 \\
\hline Age & 286 & 13.7727 & 1.3008 & 866 & 13.7252 & 1.2986 & 1,227 & 13.7628 & 1.3709 \\
\hline Serious illness $($ yes $=1)$ & 293 & 0.1809 & 0.3856 & 883 & 0.1891 & 0.3918 & 1,260 & 0.1786 & 0.3831 \\
\hline Is it an only child(yes $=1$ ) & 293 & 0.3618 & 0.4813 & 883 & 0.2242 & 0.4173 & 1,260 & 0.1667 & 0.3728 \\
\hline $\begin{array}{l}\text { Mother who graduated from elementary } \\
\text { school and below }\end{array}$ & 293 & 0.3686 & 0.4833 & 883 & 0.3918 & 0.4884 & 1,260 & 0.4421 & 0.4968 \\
\hline Mother graduated from junior high school & 293 & 0.5119 & 0.5007 & 883 & 0.4813 & 0.4999 & 1,260 & 0.4540 & 0.4981 \\
\hline Mother graduated from high school & 293 & 0.1092 & 0.3124 & 883 & 0.1155 & 0.3198 & 1,260 & 0.0944 & 0.2926 \\
\hline Mother's college degree or above & 293 & 0.0102 & 0.1008 & 883 & 0.0113 & 0.1059 & 1,260 & 0.0087 & 0.0931 \\
\hline $\begin{array}{l}\text { Father who graduated from elementary } \\
\text { school and below }\end{array}$ & 293 & 0.3686 & 0.4833 & 883 & 0.3918 & 0.4884 & 1,260 & 0.4421 & 0.4968 \\
\hline Father graduated from junior high school & 293 & 0.5119 & 0.5007 & 883 & 0.4813 & 0.4999 & 1,260 & 0.4540 & 0.4981 \\
\hline Father graduated from high school & 293 & 0.1092 & 0.3124 & 883 & 0.1155 & 0.3198 & 1,260 & 0.0944 & 0.2926 \\
\hline Father's college degree or above & 293 & 0.0102 & 0.1008 & 883 & 0.0113 & 0.1059 & 1,260 & 0.0087 & 0.0931 \\
\hline Whether living with grandparents $($ yes $=1)$ & 272 & 0.4118 & 0.4931 & 853 & 0.2860 & 0.4522 & 1,209 & 0.7130 & 0.4526 \\
\hline Pocket money every week & 270 & 34.7148 & 78.6945 & 841 & 26.8288 & 56.5140 & 1,211 & 27.4699 & 39.6109 \\
\hline Strict homework test $($ yes $=1)$ & 293 & 0.9010 & 0.2991 & 883 & 0.9468 & 0.2246 & 1,260 & 0.9270 & 0.2603 \\
\hline School $\operatorname{rank}($ best $=1)$ & 293 & 0.1092 & 0.3124 & 883 & 0.1506 & 0.3579 & 1,260 & 0.1444 & 0.3517 \\
\hline
\end{tabular}


Obvious differences can be seen from the performance. The cognitive performance of the left-behind children whose father is at home is significantly lower than the other two categories, followed by the parents who are not at home. In addition, the scores of left-behind children whose fathers are at home are about 66 in Chinese, mathematics, and English, which are significantly lower than those of left-behind children whose mothers are at home and whose parents are not at home.

It is also worth noting that the allowance for the children of the father at home is about 35 yuan per week, and the allowance for the remaining children is about 27 yuan per week. The severity of the homework test is also significantly lower than the other two categories. Left-behind children whose fathers are at home are less likely to go to the best schools. This shows that the father alone is not enough to discipline his children at home, and he fails to provide better care for his children's study and life.

\subsection{Regression Results}

After three regressions, it can be seen from the following regression results that the father's negative impact on the children's performance at home is very significant. This may be because the mother goes out alone and the father asks the children to do housework and farm work at home. When the mother goes out to work, the frequency of interaction with her mother will decrease. Due to the lack of mothers' discipline and guidance, children's time spent watching TV and surfing the Internet, the frequency of being late and skipping classes, and the probability of making bad friends may all increase. Because they did not feel the parents' expectations of their own education, the learning performance of the left-behind children whose father was at home was significantly lower than other children.

It can also be seen from the table that boys' scores in non-linguistic mathematics are significantly lower than girls, which is also in line with reality. According to previous studies, girls' scores are better than boys in elementary and junior high school. The impact of children's pocket money on performance is also significant. It can be seen that the coefficient of pocket money is significantly negative, indicating that the more pocket money a child has each week, the higher the probability of a decline in their performance. This is probably because the child does not have a deep concept of money. When there is a lot of pocket money, the child will think of buying things that are not related to learning, or going online to play games, etc., which are all reasons for the poor performance of the child.

It is also worth noting that the severity of parents' homework tests for their children only has a significant impact on the children's cognitive performance, and the impact coefficients on Chinese, mathematics, and English are positive, but not significant. The severity of parents has a positive effect on cognitive performance.
Table 3: Regression results

\begin{tabular}{|c|c|c|c|c|}
\hline Variables & $\begin{array}{l}\text { cognitive_c } \\
\text { ompetence }\end{array}$ & $\begin{array}{c}\text { chinese } \\
\text { score }\end{array}$ & math_score & $\begin{array}{c}\text { english_ } \\
\text { score }\end{array}$ \\
\hline \multirow[t]{2}{*}{ monther_home } & -0.0369 & -0.0815 & 0.515 & -0.0624 \\
\hline & $(0.0291)$ & $(0.336)$ & $(0.355)$ & $(0.341)$ \\
\hline \multirow[t]{2}{*}{ father_home } & $-0.212 * * *$ & $-2.277 * * *$ & $-3.106^{* * *}$ & $-2.825 * * *$ \\
\hline & $(0.0504)$ & $(0.582)$ & $(0.613)$ & $(0.589)$ \\
\hline \multirow[t]{2}{*}{ none } & $-0.0941 * * *$ & 0.0998 & 0.297 & 0.524 \\
\hline & $(0.0249)$ & $(0.288)$ & $(0.304)$ & $(0.292)$ \\
\hline \multirow[t]{2}{*}{$\operatorname{sex}$} & -0.0187 & $-5.720 * * *$ & $-1.113 * * *$ & $-5.617 * * *$ \\
\hline & $(0.0121)$ & $(0.140)$ & $(0.148)$ & $(0.142)$ \\
\hline \multirow[t]{2}{*}{ age } & $-0.0599 * * *$ & $-0.210 * * *$ & $-0.305^{* * *}$ & $-0.339 * * *$ \\
\hline & $(0.00502)$ & $(0.0578)$ & $(0.0611)$ & $(0.0586)$ \\
\hline \multirow[t]{2}{*}{ disease } & 0.0129 & -0.0898 & -0.280 & -0.244 \\
\hline & $(0.0174)$ & $(0.201)$ & $(0.212)$ & $(0.204)$ \\
\hline \multirow[t]{2}{*}{ only_child } & $0.180^{* * * *}$ & $-0.376^{* * *}$ & -0.239 & -0.154 \\
\hline & $(0.0138)$ & $(0.159)$ & $(0.168)$ & $(0.161)$ \\
\hline \multirow[t]{2}{*}{ pocket_money } & $-1.87 \mathrm{e}-06$ & $-0.0108 * * *$ & $-0.0128 * * *$ & $-0.0109 * * *$ \\
\hline & $(0.000119)$ & $(0.00138)$ & $(0.00146)$ & $(0.00140)$ \\
\hline \multirow[t]{2}{*}{ strict } & $0.0947 * * *$ & 0.390 & 0.640 & 0.481 \\
\hline & $(0.0325)$ & $(0.376)$ & $(0.398)$ & $(0.380)$ \\
\hline \multirow[t]{2}{*}{ Constant } & 0.134 & $68.85 * * *$ & $71.65 * * *$ & $73.66 * * *$ \\
\hline & $(0.113)$ & (1.312) & (1.385) & (1.328) \\
\hline monther_edu & YES & YES & YES & YES \\
\hline father_edu & YES & YES & YES & YES \\
\hline school_rank & YES & YES & YES & YES \\
\hline Observations & 17,954 & 17,525 & 17,517 & 17,518 \\
\hline R-squared & 0.115 & 0.107 & 0.022 & 0.105 \\
\hline
\end{tabular}

Standard errors in parentheses: $* * * \mathrm{p}<0.01, * * \mathrm{p}<0.05$

\section{Conclusions and Recommendations}

\subsection{Conclusion}

This paper uses CEPS baseline data to conduct an empirical analysis. By comparing the learning performance of rural left-behind children and non-left-behind children, it focuses on the impact of the lack of care caused by parents' migrant work on the learning performance and cognitive abilities of left-behind children. The results show that staying behind does have a certain negative impact on children, but this effect is different among left-behind children. Compared with children whose mothers are at home and whose parents are not at home, children whose fathers are home alone have worse academic performance and are not as good as other children in cognitive ability. It is reflected from the side that due to the traditional division of family roles, fathers have neglected the cultivation of parent-child relationship, and they have not cared enough about their children's education, life and psychology, and failed to provide them with good learning help. For the other two types of left-behind children, the left-behind status has no significant impact on their academic performance and cognitive ability. Therefore, it shows that mothers have a huge influence on children's study and life. 
The absence of parents at home will make the child's cognitive development poor, which is due to the negative effects brought about by the lack of care by others.

\subsection{Recommendation: Build a Care System for Left-behind Children}

Staying behind will bring certain negative effects to children, so we must pay attention to and attach importance to the education of left-behind children. It is necessary for the government, society, family, community and other diverse entities to participate together to build a care system for left-behind children, including education support, services for left-behind children, etc.:

5.2.1 The government should take measures to improve the education and welfare of left-behind children

Affected by the household registration system, it is difficult for the children of migrant workers to enter the city and receive education with migrant workers. Therefore, in the design of employment, medical care, housing and education policies, migrant workers and their families should be given a full range of care, from the top-level policy design conceptually weaken the urban-rural binary division of interests, design a flexible and diverse medical and educational linkage mechanism for the migration and flow of the population between urban and rural areas, ensure the education and welfare of left-behind children, and ultimately promote educational equity; on the other hand, strengthen the macro-control of rural education investment and resource allocation to make rural compulsory education from "unbalanced development" to "coordinated development" to make up for the weakening of rural family education; in addition, the rural economy should be vigorously developed, and the minimum wage and maximum working hours should be increased to attract going out. Migrant workers return to their hometowns for employment, so that migrant workers can have more time and energy to communicate with their children, and solve the education dilemma of left-behind children from the source.

5.2.2 Establish a caring linkage mechanism based on the community

Through the establishment of caring service positions and team building, establish a community management and care linkage mechanism[15]. The first is to establish files for left-behind children and strengthen the dynamic monitoring of left-behind children; the second is to establish a caring service position for left-behind children and recruit volunteers based on rural libraries, youth education bases, family activity rooms or various village activity centers. Organize activities on a regular basis[16]; Third, select responsible families or caring people through forms such as "surrogate parents" or "neighborhood assistance", and adopt full-custodial or semi-custodial forms to solve the worries of the families of left-behind children[17].

5.2.3 Schools should pay enough attention to the education of left-behind children

The school is the basic unit that undertakes the education and teaching of left-behind children, but the relevant laws and regulations do not make it clear that there is an entrusted guardianship relationship between left-behind children and their schools. In view of the weakening of family education functions and the inadequate guardianship of temporary guardians, schools should serve as the main front for the education of left-behind children, and they should be obliged to assume the responsibility of education and management of left-behind children. We should strengthen the construction of school infrastructure and teaching staff, and strengthen the social responsibility of regular education and special care for left-behind children through measures such as resource allocation, caring service mechanism, caring team building, mental health counseling, and living allowances for left-behind children. In the entire chain of education for left-behind children, schools should play the role of the main position. This point needs to form a consensus from top to bottom and be reflected in relevant laws and regulations.

5.2.4 Families of left-behind children should rationally divide labor, respond to calls, and strengthen education responsibilities

To solve the problem of left-behind children's education in rural areas, we must start with family education, strengthen the educational responsibilities of parents of left-behind children, and actively create a good family atmosphere." The first is to improve the legal responsibilities of child guardianship, monitor or supervise the guardianship of left-behind children, organize experts and school teachers to train and guide guardians, and especially emphasize the responsibility of fathers to guard and teach left-behind children; second, rely on community construction to be effective parents' self-discipline mechanism requires fathers to recognize their role in family education, regularly reflect on the lack of education for their children, and effectively pay attention to and accompany left-behind children.

\section{References}

[1] Felipe Combs, Zhao Baoheng, \& Li Huan,. World education crisis, people's education Press, pp.241, 2000.

[2] Nelnoddings. From the family: care and social policy, Educational Science Press, pp.62, 2006.

[3] Duan Chengrong, Lu Lidan, Wang Zongping, Family education and school education of rural left-behind children under the background of urbanization, Peking University Education Review, pp.13-29+188-189, 2014.

[4] Duan Chengrong, Lu Lidan, Wang Zongping, The school and academic performance of left-behind children - based on the dual perspectives of educational opportunities and educational outcomes, Youth Studies, pp.50-60+95, 2013.

[5] Zhou C, Sylvia S, Zhang L,et al, China's left-behind children: impact of parental migration on health, nutrition, and educational outcomes, Health affairs, pp.1964, 2015 
[6] Zhang Liang, A Study on Left-behind experience and rural children's school termination: an empirical analysis based on the Chinese family tracking survey, Youth Exploration, pp. 74-82, 2017.

[7] Yang Juhua, Duan Chengrong, Comparative research on educational opportunities of migrant children, left-behind children and other children in rural areas, Population Research, pp.11-21, 2008.

[8] Wan Jin, Analysis of the causes of the educational problems of the rural left-behind children based on the theory of relative deprivation, Journal of Hubei University of Economics (Humanities and Social Sciences), pp.16-19, 2019.

[9] Hu Feng, Li Shantong, The impact of parents' migrant workers on the education of left-behind children in rural areas-an empirical analysis based on the survey of migrant workers in 5 cities, Management World, pp.67-74, 2009.

[10] Li Yunsen, Self-selection, parental going out and left-behind children's learning performance: an empirical study based on surveys in underdeveloped areas , Economics (Quarterly), pp.1027-1050, 2013.

[11] David McKenzie, Hillel Rapoport, Can migration reduce educational attainment? evidence from Mexico, Journal of Population Economics, pp.1331, 2011.

[12] Ming Wen, Danhua Lin, Child development in rural China: children left behind by their migrant parents and children of nonmigrant families, Child Development, pp.120, 2012.

[13] Xu Qi, The influence of parents going out on the academic performance of left-behind children in rural areas, Youth Research, pp.39-51+92, 2018.

[14] Ji Caijun, Educational support for left-behind children from the perspective of education equity: an empirical investigation based on the difference between left-behind and non-left-behind children, Elementary Education, pp.48-57+81, 2016.

[15] Ji Caijun, The educational dilemma of left-behind children from the perspective of differences in learning - an empirical investigation based on left-behind and non-left-behind children, Shanghai Educational Research, pp.41-46, 2016.

[16] Chen Jing, Wang Ming, Educational poverty alleviation and left-behind children care system construction-based on the "book guided reading test" in Village T, County D, Journal of Northwest Sci-Tech University of Agriculture and Forestry (Social Science Edition), pp.24-34, 2018.

[17] Deng Lijun, Deng Qian, Yang Wenjian, Research on the compensation education model for left-behind children based on rural bookstores, township libraries, and schools, Journal of the National Library of China, pp.19-23, 2013. 